\title{
IDENTITY AND CAREER CHOICE IN MUSIC
}

\author{
Julie Jaffee Nagel
}

Several provocative hypotheses and questions were posed at the Third and Fourth International Conferences on Cultural Economics in 1984 and 1986. After examining the disparate relationship between artists' training and earnings, Wassall and Alper proposed that, "the public stereotype of the artist is of a person who is in many ways different from the 'rest of us" (1984, p. 213). Gray suggested that "performing artists must be a pretty peculiar breed; their behavior does not seem to make much sense. Why would anyone seek employment in a profession that pays notoriously low average salaries and entails equally notorious unemployment and underemployment?..Clearly these people are behaving in an irrational manner. Or are they?" (1986, p. 231). Following the Fourth International Conference on Cultural Economics, Dick Netzer made the following comment in a letter to me, "...the simple models that we economists use to understand how the performing arts 'work' predict that almost no one would choose to be a muscian, but that once one had made that choice because of the supposed 'psychic income' from the career, one would never leave it".

As a musician and a psychologist, I, too, have been puzzled by the questions raised by economists. Thus, this paper reflects an effort to probe these same issues. In doing so we will not deal with census data nor economic models, but will share some results of personality inventories and clinical interviews as extracted from my larger study on the relationship between identity formation and career choice in music. We will illustrate how both intrapsychic and interpersonal issues, in addition to economic variables, must be considered in a discussion of what is unique about the music profession and why performing musicians are attracted to their occupations. Therefore the themes for this paper are embedded in a complex contrapuntal score. 
A career in the performing arts forces many musicians to deal with harsh economic and social realities such as a problematic job market, low pay, seasonal employment and dependency on others for financial support. When obtaining data about alumni activities, the Juilliard School requests former students to describe their careers according to their "1) principal occupation - the one which is most important to you, 2) secondary occupation, and 3) third occupation", thus illustrating the uncertain nature of employment in the arts and the probability of multiple employers. Nevertheless, many musicians hold fast to the belief that their work is a privilege and actively continue to pursue performance opportunities. This paper is based upon the assumption that, despite a professed love for their work and a willingness to accept low wages, performing musicians often face a conflict which encompasses pragmatic as well as psychological aspects of their lives. For most people, the choice between a satisfying career and an income not commensurate with their training and expertise would create a dilemma. And a closer look at the musical performer suggests indeed, what which appears to be consonant, i.e., "psychic income" and "internal satisfaction", has dissonant overtones. There is conflict inherent in the decision to pursue music as a career for some musicians, and this conflict often can be detected by examination of how a career choice is made and how that choice is related to the musician's identity.

The following profile of performers, ex-performers, and non-performers emerged in a study done at The University of Michigan (1987): 1) ninety percent of 61 subjects, a subset of the original sample $(\mathrm{N}=82)$, had studied an instrument seriously since before they were twelve years old; 2) forty-six percent had played an instrument since before the age of seven; 3) ninety-two percent of the subsample complained of stage fright; 4) sixty three percent felt their performances were adversely affected due to severe nervousness.

Parents gave mixed messages to their talented offspring as their early support of music lessons and performing activities decreased from 82 percent to 56 percent for mothers and from 74 percent to 51 percent for fathers. There was fear on the part of the parents that a music performance occupation would lead to an unstable lifestyle, dictated, in part, by economic insecurity. As one subject explained, "my parents don't want me to wind up eating cat food in New York City". It is not surprising, then, to find that overall 60 percent of the eighty two subjects in the total sample were experiencing conflict or dissatisfaction regarding their career choice in music. (Conflict was defined as indecision over career plans, wrestling with vocational alternatives, 
and complaints of debilitating stage fright). Obviously much time, funds for lessons, and life-space are invested in pursuit of a career in music performance, usually at the expense of exploring other options. If many years of preparation and dreams of a career are threatened by self-doubt, debilitating stage fright, and financial insecurity, musicians abruptly find themselves in an unenviable situation.

Despite these findings, where 55 percent of my sample complained of external frustrations, i.e., low pay, problematic job market, politics in auditions and competitions, 70 percent, nevertheless, spoke of the intrinsic rewards of a career in music performance. Statements such as, "I feel unique", "I had no choice", "I feel special and different" provided leitmotifs even as themes of indecision about career choice resounded over the affirmation of vocational satisfaction. Psychic income often appears to support psychic needs even if it paradoxically sabotages economic security. So I must persist with my initial questions: if a career choice in music performance is not predicated by a desire for financial security and social status, if education and training do not necessarily impact upon earnings, if external conditions present obstacles and frustration, why do individuals choose a career in the performing musical arts and how is this vocational decision made?

When focusing upon a psychological model of career choice, it is possible to recast vocational decisions into the context of identity formation. And while occupational choices are over determined for every individual (regardless of vocation), one model that is suitable for deeper examination into the career choice of musicians (as well as others) suggests that commitment to - or conflict about - careers reflects particular types of decision-making that are dominant typically in late adolescence/young adulthood. During this critical developmental period, young adults synthesize their sameness, their differences, and the continuity of their parents as part of a process that results optimally in a definition of self. Commitment to an occupation is one important outcome of this process; the nexus for one's personal identity is related intimately to this decision. However, the construct, "identity", has proven difficult to study empirically.

The Identity Status Interview (Marcia, 1966) assesses personality and occupational commitment as it operationalizes the psychosocial theory of Erik Erikson $(1959,1963)$. As such, the Interview evaluates adolescent identity formation in the domains of occupation, religion, and politics. (For the purpose of this paper, I limit discussion to identity and occupation. An examination of the relationship between voca- 
tional choice in music and its relationship to politics and religion is found in my complete study.) Although the Interview does not produce a moving picture of the dynamic process of arrival at a particular identity stage or predict how future growth will be shaped, it has been shown to take effective snapshots of the "image of people stopped at a particular moment" (Donovan, 1975, p. 54).

Paralleling Erikson's theory, Marcia's schema includes four levels of commitment (or lack of commitment), each representing varying degrees of conflict and crisis resolution regarding occupational choice. The term crisis connotes a struggle in making decisions while commitment refers to certainty of choice, including a reluctance to change directions. Adolescents and young adults evaluated on the Identity Status Interview are placed in one of four categories. These categories are labeled Achieved, Foreclosed, Moratorium, and Diffused.

When applying the model to musicians, individuals classified Identity Achieved seek careers in music performance but have tried or thought seriously about other options and have weighed the pros and cons of their decision. Ultimately, they have arrived at their own conclusion, perhaps despite parental objections and, most importantly, are believed to be relatively conflict-free. Identity Foreclosed individuáls, like Identity Achieved, maintain that a career in music is their goal. However, unlike the Achieved musicians, these people never have considered career alternatives. Generally, they are following a career path or life style predetermined by their parents, their ego defenses are brittle, and their self-esteem is dependent upon authority figures (which include parents, teachers, and audiences). Identity Moratorium individuals are musicians currently in crisis about their career plans in the performing arts. Currently undecided and weighing alternatives, these individuals are considering their talent and potential, parental objections, and social and economic problems that confront performing artists. The last category in this paradigm suggests that Identity Diffused individuals may pursue music professionally because they enjoy music and the attention performance brings; however, they also feel other professions can offer equal satisfaction. They have not explored any particulars about what musicians "do" and their smorgasbord attitude of "everything looks good", reflecting a lack of commitment as well as a lack of struggle, permits them to switch to other work if a music career does not materialize.

The following vignettes illustrate the four Identity Status styles of thinking about career choice. 
Achieve (Note how exploration preceded commitment.)

A saxophone student told of playing his instrument in night clubs while he was a pre-med major. However, he was not happy when studying to be a doctor. He reports that although his parents' plans for him included "my son, the Dr." he found that music is a way of expressing myself - what's inside. I can't do that with words".

A clarinetist decided to major in music during her junior year of high school. Valedictorian of her class, she found that for her "academics were easy, music was challenging". However, her teacher in college advised her to get out of music. She reports "agonizing over this recommendation, trying to double major in journalism only to return to music. Getting away from it made me better".

Foreclosed (Note how decisions are made without exploration and also how closeness to family is emphasized.)

A trumpet player "never considered anything else. I want to influence people in positive ways through music. I plan to live at home while I major in music at college".

A clarinetist also lived at home throughout her undergraduate and graduate schooling. "I decided in second grade to go into music. I never considered any other career. I would never feel like myself without music".

Moratorium (Note the active conflict.)

A graduate student in trombone is not enjoying school. He says he stays to get his degree so that he can get a job. However, "if I had to do it over, I might not go into music. You're not respected by academics; you live in a practice room. But I would like to make music and bring it to other people". A voice student is expressing her conflict and avoidance of commitment by double majoring in music and psychology. "I'm keeping myself open. Psychology is for me...until I have a good voice lesson".

Diffused (Note the confusion and lack of commitment.)

An organist reports "I don't know what I plan to do. I don't want a church job. Medicine is fascinating; I toyed with the idea of being a brain surgeon, but my mother noticed my knack for music".

A young woman describes her decision to study saxophone: "I originally wanted to play flute in fifth grade band, but the band director said there were too many people and said I had to choose something else, and I had to choose that day, so I said saxophone sounded 
neat, I think I'll play that". Currently, her career objectives are nebulous, although she talked of looking for a university position. "The colleges that have openings aren't places that are particularly appealing, like Arkansas and stuff'.

As predicted, distinct patterns emerge when Achieved, Foreclosed, Moratorium, and Diffused musicians speak of their career choice. This is seen not only in the above statements that illustrate how career choice is made, but also in the way Identity Status is related to the subjects' stage fright. For example, there was a significant difference $(F=2.73$, p.05) among Identity Status Groups. Further, Scheffe allowances indicated that Diffused, Moratorium, and Foreclosed subjects, respectively, were higher in performance anxiety than Achieved subjects. While Achieved and Foreclosed individuals appear similar in their professed certainty about career choice, the literature suggests that Foreclosed individuals are thought to be more defensive than seems apparent. By contrast, Achieved individuals have worked through troublesome and conflicted issues, perhaps contributing to their lower performance anxiety. It is not surprising that Moratorium individuals, experiencing crisis, or Diffused musicians, uncommitted to a music career, score higher performance anxiety than do Achieved individuals.

Further, the Identity Status literature suggests that particular developmental antecedents determine why vocational commitment or conflict is inherent in decision-making regarding occupational choice. Although time does not permit me to report on how I operationalized and analyzed the psychological precursors of Identity Status (for a full discussion, the reader is referred to the 1987 study by the author), it should be emphasized that interpersonal relationships with parents during childhood cast a shadow, sometimes a pall, over the young adult's career path. By way of brief explanation, Achieved individuals are believed to grow up in homes where there is some tension among family members, resulting in moderate negative evaluation by the child toward the parents. Foreclosed individuals come from child-centered homes and have a "love affair" with their parents. This relationship is reported to be "stifling as well as luxuriant" (Marcia, 1976), and results in individuals feeling there is too much to lose if they stray too far from the parents' ideals. Moratoriums are ambivalent toward their parents, resulting from inconsistent attitudes generated by the family toward the child. Frequently, Moratoriums are rebellious and engage in a power struggle with authority figures. Diffused individuals have parents who are indifferent, rejecting, uninvolved, and detached. Con- 
sequently, the offspring feel alienated, inferior, and hostile toward authority.

Data on family pathology and performance anxiety help illustrate how personal and professional lives are intertwined. For example, the relationship between high family pathology and performance anxiety approached statistical significance with $F=3.09$ and $p=.08$. (Pathology was defined as violent arguments in the family, lack of communication among family members, neglect by parents, and volatile interpersonal interactions in the family). These data imply that the anxiety and stress generated by unhealthy family interactions find their way into some musicians' professional lives. Withdrawal to the solitary ritual of practice in search of virtuosity and musical perfection may be adaptive for the young musician whose home life is tumultuous. However, the adult musician can pay a high price, emotionally, physically, and economically, if underlying issues are not addressed. And although it is not implied that the music profession is filled with performers who grew up in domestic turmoil, it is of interest to note the relationship between performance anxiety and family pathology found in the subjects in this study.

Overall, it appears that the musicians in the study are dealing with separation and individuation issues that are made salient by enrolling in college. In fact, the data suggest that the pursuit of music as "salvation" from problematic domestic issues which become buried in the comfort of the isolated practice ritual resulting in accomplishment on an instrument, creates an illusion of security for some young musicians. Sixty percent of sampled subjects were found to be experiencing conflict. These are individuals who are less than committed to their career choice (Moratorium and Diffused) or have not explored vocational alternatives (Foreclosed). This conflict is reflected in their career choice statements, their performance anxiety, and in their ideals internalized, the Foreclosed are able to maintain loving and approving objects. However, this does not lead to individuation.

Marcia (1976) maintains that "ideal' child-rearing practices may not produce 'ideal' children if ideal is understood to mean the ability to cope with a world of myriad values and pressures" (121). The inability to separate emotionally from parents may create as many problems as it seems to solve. Certainly, for performing musicians, separation is required to appear autonomously on the concert stage or play a solo in a symphony. Conversely, the Moratorium status exhibits greater autonomy, enabling these musicians to face (if not immediate- 
ly solve) their conflicts. The Diffused tangled in a "Catch 22 " and motivated by anger, are unable to make an emotional move away from parents, yet find staying close results in further disappointment and disillusionment. Thus, Achieved individuals are believed to have achieved full independence from early relationships and can interact productively in society through their work. According to Marcia (1976), "our Identity Achievements, in particular, seemed to be telling us that some independence between parents and children, perhaps even some antagonism, is a necessity for psycho-social growth" (121). Thus, in the ongoing, dynamic process of growth and maturation, identity becomes a meaningful and integral by-product of career choice just as career choice is a reflection of personality.

The concert hall can represent a platform for communication, for intimacy, for distance. The stage or music studio may be thought of as a theater where covert and overt scripts are exchanged between musicians, teachers, and audience members; conflicts regarding both self and others are reactivated and sometimes exacerbated or resolved through music performance. Therefore, music careers have the potential to provide an important outlet for the performer's ego adaptation.

I began this paper by posing questions; I will not conclude with answers. The findings on Identity Status and career choice raise additional issues that must be addressed. Early developmental experiences spun in a web of interactions with the family undoubtedly shape subsequent attractions and attitudes toward music careers. Does an individual's gravitation to music during childhood suggest different types of attachments and interactions with parents than a career choice made later in adolescence or adulthood? Does the early choice of music as a career pose individuation problems later in life? Certainly, early specialization on an instrument and an intent on a music career narrows choices for exploration of non-musical alternatives. While this may be desirable for technical and artistic proficiency, it seems counterproductive for identity integration and vocational investigation. Yet one cannot begin to become a serious musician at the age of sixteen, eighteen, or twenty five. Thus, the life-long investment in artistic training not only makes it difficult to take advantage of a broad education but also creates unique problems should the artist decide to change career directions later in life.

Certainly the early specialization of musicians raises questions about the function of an undergraduate college curriculum. Should 
colleges and music schools endorse professional training beginning in the freshman year or would it be desirable for them to create opportunities for exploration of a variety of alternatives while simultaneously providing support for the resolution of identity crises? Marcia writes that "colleges can become different kinds of places if we begin to look at them in terms of the human life cycle rather than as professional certifiers" $(1976,127-128)$.

Since vocational preferences are complex decisions, born from multiple determinants that impact upon an entire life-space, the pursuit of a career that is incompatible with one's personality potentially breeds dilemmas, not only in terms of job satisfaction but also in psychological well-being. Data on Identity Status and career choice highlight this concept. With jobs in the arts so scarce, financial remuneration often inadequate, and competition for funding so fierce, it is imperative that mental health professionals, educators, economists, arts administrators, and policy analysts understand not only the unique pragmatic issues that confront performing musicians but also develop a sensitivity to the centrality of career choice in the dynamic process of personality development.

University of Michigan

\section{References}

Donovan, J.M. "Identity Status and Interpersonal Style", Joumal of Youth and Adolescence. Vol. 4, No. 1., 1975, 37-55.

Erikson, E.H. Identity and the Life Cycle. New York: W.W. Norton \& Co., Inc. 1959.

Erikson, E.H. Childhood and Society. (2nd edition). New York: W.W. Norton \& Co., Inc., 1963.

Gray, C.M. "The Economics of Arts Labor Markets: An Overview", Artists and Cultural Consumers, D.V.Shaw, W.S. Hendon, \& C.R. Waits, (eds.), Proceedings of the Fourth International Conference on Cultural Economics, Vol. III, 1986, 66-76.

Marcia, J.E. "Development and Validation of Ego-identity Status", Joumal of Personality and Social Psychology, Vol.3, 1966, 551-558. Marcia, J.E. " Studies in ego identity." Unpublished research monograph. Simon Fraser University, 1976. 
Nagel, J.J. An Examination of Commitment to Careers in Music: Implications for Alienation from Vocational Choice. Unpublished doctoral dissertation. University Microfilms, 1987.

Wassall, G.H. \& Alper, N. "Determinants of Artists' Earnings", The Economics of Cultural Industries. W.S. Hendon, N.K. Grant, D.V. Shaw, (eds.), Proceedings of the Third International Conference on Cultural Economics, Vol. 1, 1984, 213-230. 